\title{
Advancing the creative development process with systems thinking and a developmental model for designers
}

\author{
Brigid O'Kane \\ University of Cincinnati, USA
}

\begin{abstract}
The traditional design process used within the automotive industry is typically accomplished with limited regard to the environment the vehicle will operate within. As a result there are many growing challenges relating to mobility that we now face. When systems thinking methodologies are integrated into the design process innovative and holistic concepts are developed, causing significant shifts in new products, processes, and services that are better suited for the environment. Systems thinking methodologies in combination with the Developmental Model for Designers enables the creation of solutions from a more informed perspective. As a result, we are discovering new and appropriate ways to develop products and systems that are holistic solutions for the challenges of today and the future.
\end{abstract}

\section{KEYWORDS}

Systems thinking; transportation; design process; industrial design

\section{Introduction - challenges of today and the future}

Currently there are more global challenges relating to transportation and mobility then ever before. These include global human pollution growth, global warming, and the depletion of natural resources. Regional challenges are also of great concern when considering anticipated increases in population and urban density. Experts predict the number of people living on the planet in 2030 will be up to eight billion. Currently, with the human population at seven billion urban regions have mobility issues. In cities today the average speed of a vehicle is 25 miles per hour, as mentioned by Mitchell, Borroni-Bird, and Burns [8] in their book, Reinventing the Automobile. Dense traffic causes congestion, and commuters travel hours one-way [3]. Parking can be expensive, hard to find, and searching for parking contributes to congestion and pollution.

The costs associated with vehicle ownership can add up when considering payments, insurance, parking, gas, maintenance, and repairs. Product Lifecycle Management (PLM) processes do not factor in the entire cost of what is really paid for mobility. When considering these costs relative to the social, financial, and environmental impacts, the "triple bottom line" for mobility and infrastructure become immeasurable. Thomas E. Lovejoy from the World Wildlife Fund states, "Conservation is sometimes perceived as stopping everything cold ... It is up to science to spread the understanding that the choice is not between wild places or people. Rather, it is between a rich or an impoverished existence for Man."

So how did we get into this situation and how do we design with this bigger picture in mind? Is it really up to science alone to spread the understanding of making better choices and developing products that solve these challenges? Are both scientific and creative perspectives needed to develop holistic design solutions?

Most automobiles and trucks are designed through traditional processes that do not include a comprehensive understanding of these broader issues or the circumstances these vehicles will operate within. Aspects of the user experience are usually considered as it relates to the vehicle only, including safety, comfort, maneuverability, efficiency, and the driving experience. These are important, but are limited in scope since they do not take into account the greater challenges of the existing system. By using this traditional design process solutions are developed in isolation, which can only produce a partial solution leading to bigger problems.

Designing and developing appropriate solutions for today's challenges should include a holistic approach. Diverse opinions and interdisciplinary teams are needed for this broader perspective in developing comprehensive solutions, not fragmented results that emerge as a

CONTACT B. O'Kane brigid.okane@uc.edu 
collection of parts. One such approach includes Systems Thinking Methodologies [9], which considers balance and social-ecological systems. There are many different definitions of systems thinking, which vary depending on the application. Author Peter Senge [12] describes systems thinking as a critical component to organizations. The approach defined in this paper applies directly to the design process. When applied, these methodologies have the potential to influence or change the trajectory of existing systems, in addition to developing new systems. These methodologies help industrial designers look at the entire matrix in context, giving them the ability to develop better creative and strategic design solutions.

Within this paper steps are described relating to Systems Thinking Methodologies and their relationship to a Developmental Model for Designers. Both approaches encourage a holistic perspective for designers and others disciplines. These models give designers a heightened sense of awareness and assist in broadening perspectives beyond the product.

\section{Adapting to new approaches in design}

Some designers adapt well as new design processes are introduced and implemented, while others do not. This adaptability is not dependent on experience or knowledge. It is related to the level of awareness a designer may or may not have with respect to the broader influences of the products they create and what they choose to do with this knowledge. As designers accumulate experience they go through developmental phases that can enhance or diminish this broadened perspective. There are phases that ultimately lead to the development of the awakened designer. This designer has a holistic world-view and the ability to adapt to changes more easily to create enhanced products and systems for the world.

\section{The developmental model for always becoming a designer}

When considering how designers develop it is important to consider how people learn in general. Various experts such as Jean Piaget [11] have developed theories of cognitive development that detail developmental stages associated with age. David A. Kolb [5], an educational theorist, focused his interests and publications on experiential learning, learning styles, the individual and social change, career development, and professional education. Additionally, Kurt Lewin's [6] work had a profound impact on social psychology and, more particularly for the purpose of this paper, on experiential learning, group dynamics, and action research. Howard Gardner [4], in his book Frames of Mind discusses how human beings have very different intellectual strengths that influence how we learn. He elaborates on seven different types of intelligences. There are many others experts who have expanded on this idea including Robyn McMaster [7], who elaborates on eight types of creative intelligences.

Industrial designers and other professionals go through phases of development, which are detailed in the Developmental Model for Designers (Fig. 1). The inspiration for this came through studying the aforementioned models and from Ken Wilber [14], who is an author and philosopher focusing on mysticism, ecology, and developmental psychology. His work formulates what he calls Integral Theory and based on this work he has founded the Integral Institute.

The seven phases to the Developmental Model for Designers are described below. One of the more important aspects of knowing these various phases is the awareness it offers relative to the next critical stage in our own personal and professional development. Designers are often intrigued by the notion of this next step in their level of awareness, and this model provides an opportunity for us to reflect upon this and consider how we might elevate ourselves through the phases.

\subsection{Phase 1 - Adolescent}

The adolescent phase can be referred to as being 'first person' and egocentric, since individuals in this phase are focused mainly on themselves. This phase is an extremely important period for children and young adults as they are exposed to art and design in the broadest sense. This exposure can influence how they view the world and their relationship to creative thinking. Children experience inventive and experimental activities at home mostly through expressive pursuits such as drawing, painting, and sculpting. Additionally, exposure to these inspiring origins in pre-college schools enhances creativity [1], which is a skill that is vitally important in problem solving.

\subsection{Phase 2 - Enchantment}

Like the adolescent phase, the phase of enchantment is also 'first person'. When young adults focus on their individual interests they may show a keen attraction to art and design. In this phase they continue to nurture creative activities. Eventually they obtain more information on related professional paths and select design as a future career choice. In this period, they experience a draw to 


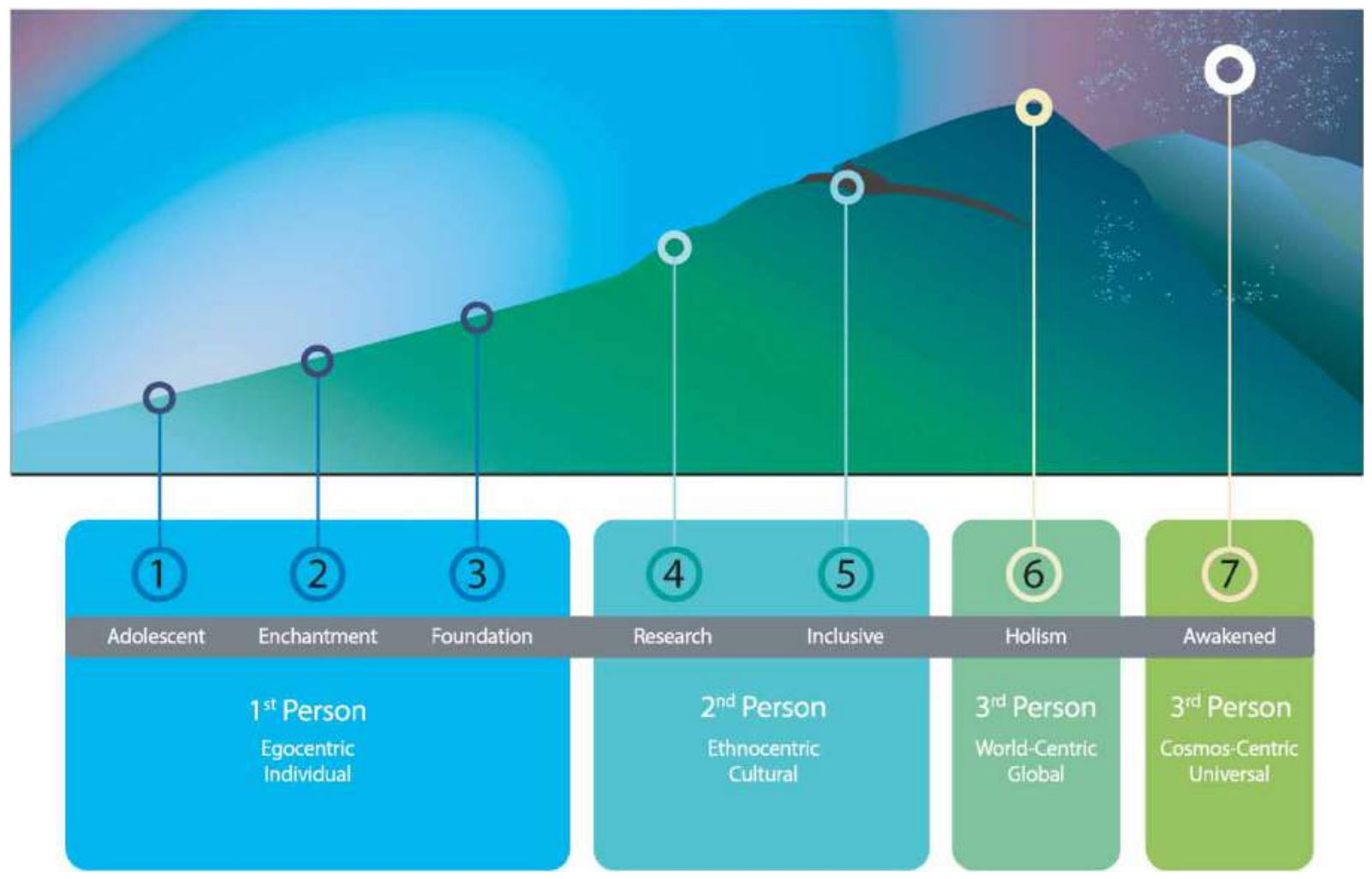

Figure 1. This image depicts the seven phases to the Developmental Model for Designers. The first three phases are focused on young children and adults as they discover their artistic talents and learn about creative career opportunities. Phases four and five occur when young designers are confronted with other perspectives relative to design, which they accept or reject. The sixth phase is the successful designer who is established in their career, and the seventh phase is the awakened designer who thinks broadly and applies systems thinking methodologies.

this field of choice and are enchanted by the prospects and opportunities it may bring.

\subsection{Phase 3 - Foundation}

The foundation phase focuses on the individual with strong expressions of intentionality. They learn core skills to formalize and actualize their ideas. They learn fundamental skills crucial to being successful in the field of design. Throughout this stage the student becomes immersed in the expressive aspects of design. They establish the basic groundwork through natural, experimental, and prepared educational experiences. This emerging designer must gain an appreciation for and a critical understanding of inventiveness and creativity in order to successfully transition through this phase.

\subsection{Phase 4-Research and creativity}

Ideally, the ethnocentric designer moves successfully through the research and creativity phase. This designer is at the 'second person' stage because they are more aware of other cultures, designers, and collaborative partners. They are also exposed to various approaches to the design process, expanded creative practices, and integrated research. Designers may have a preference relative to intelligent approaches (creative) and intellectual approaches (scientific). This may cause friction or a divide as one group tries to establish an air of superiority over the other. Then, conflicts and tensions develop between designers with different intellects or intelligences. It is important to note that some designers never develop past this stage and friction lingers.

\subsection{Phase 5 - Inclusive}

The inclusive designer is also 'second person' and ethnocentric. In this phase creative and scientific approaches are appreciated and respected. Successful collaborative practices emerge and these designers develop an appreciation for other approaches and disciplines because they contribute to the design development process. These inclusive designers have a strong individual identity since they are self-expressed, aware of individual preferences, and are culturally aware. However, they embrace other perspectives and the fiction described in phase 4 dissolves and interdisciplinary partnerships thrive. 


\subsection{Phase 6 - Holism}

Holism is in the 'third person' and is world-centric, or from a global perspective. In this stage individual designers are exposed to multicultural facts or experiences. They become aware of the interconnection of the world as a whole. They are knowledgeable of various systems approaches to design. This phase enables designers to experience an increase in consciousness and perspectives. They also develop an appreciation for all the individuals in the previously mentioned phases.

Many established professional designers are in this phase. These designers are successful in terms of a having attained a respectable title, wealth, position, honors, and the like. However, many of these successful designers stop at this phase, as they are unaware that a higher level of design awareness can be achieved.

\subsection{Phase 7-Awakened}

The awakened designer thinks in fourth person and from a universal or cosmos-centric perspective. The designer who reaches this stage is characterized as transpersonal. They become extremely advanced in their thinking and approach to design. They are capable of creating products, systems, and services at the highest level. These designers develop the ability to breakaway from the collective mainstream mindsets and think alternatively in all directions. Others are integrated into their all-inclusive view as necessary contributors.

\section{Introduction systems thinking for the awakened designer}

Designers in phase 4 and beyond are capable of facilitating holistic approaches to design that include System Thinking Methodologies, which enables them to link critical points of information with meaningful connections and insights. This ability allows designers to more effectively solve problems and develop solutions.

The awakened designer in phase 7 has an innate ability to observe, make connections, and respond to a design challenge with deep compassion and understanding. They have a deep-rooted appreciation and respect for natural systems. They implement Compassionate Design Practices, which lead to solutions that are good for the earth and all life on it. They also create systems that are in harmony with the world and the environment.

The traditional design process separates disciplines into silos, and this division causes conflicts that ultimately lead to the creation of products that are not designed well and create problems. Awakened designers have exceptional observation skills for examining problems, and they experience deep connections and empathy as they relate to specific circumstances. They link silos into patterns of systems, from which honest debates about real issues emerge. Authentic conversations are necessary for constructive problem solving. This is the platform from which transformation can happen. In this way we are able to resolve positive ways to go forward. Awakened designers also become powerfully motivated to change existing systems. They have the ability to slow down and dwell on the challenges, not just from their minds but also from their hearts. In this way they respond from a place of enlightenment.

\section{Overview of system thinking methodologies}

Systems thinking methods guide a holistic approach to phenomenon relative to product design in the broadest sense. Although the examples given in this paper focus on transportation and mobility, the steps of Systems Thinking Methodology (Fig. 2) can be applied to any product. There are three major areas of focus that include; a) the product, b) the people that may use the product, and c) the environment in which the product will be used

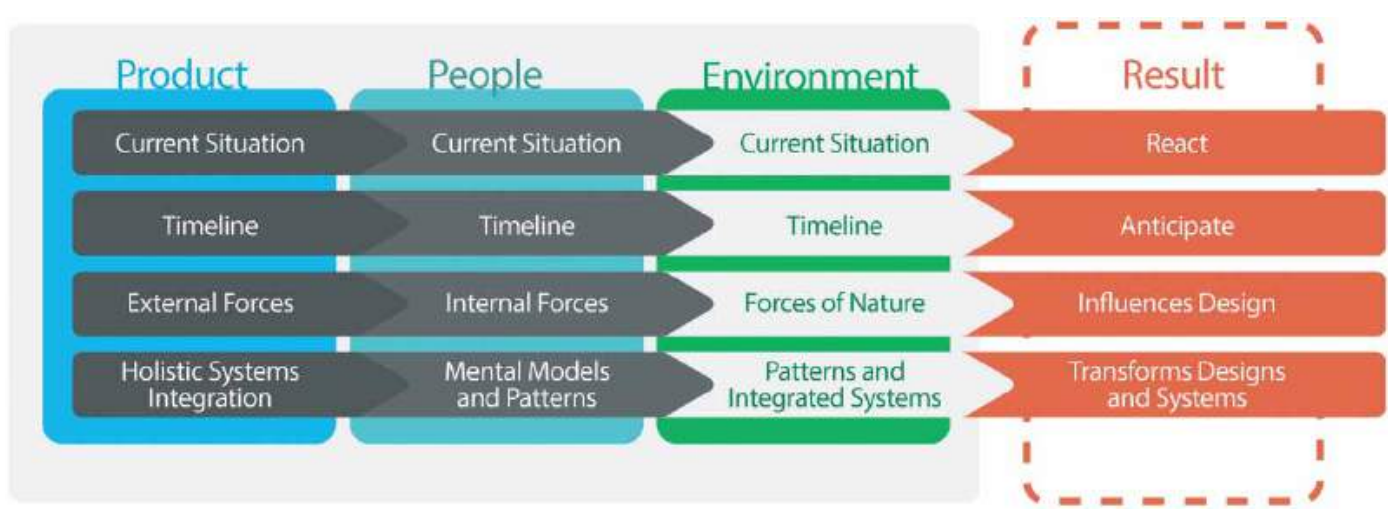

Figure 2. This diagram of the systems thinking process is essential to the product development process, especially for large-scale projects relating to mobility and transportation. This systems thinking strategy applies to products, people, and the environment. 
or operated. Exploring these areas in depth enables us to better understand their relationships. The steps for researching and exploring these three areas include; 1) the Current Situation, 2) Timelines, 3) Forces, and 4) Holistic System Integration. These steps are explored during the design development process, which enhances the designer's knowledge relating to the product. They find deeper insights into the broader issues, and become more aware of the product, the user nuances, and the surroundings. This enables them to develop a deeper holistic point of view.

Knowledge gained through documenting the current situation in three areas (product, people, and environment) gives us the ability to react. When looking closely at the product we collect information about the current situation, which is similar to benchmarking. Observing the current situation of people helps us understand the user better and how they may react to the introduction of new products or systems. Exploring aspects of the environment is helpful in creating products that are integrated into the broader system as a whole. Understanding the current situation is critical; however, it is limited in scope.

Collecting information in the form of timelines can inform the development process giving designers the ability to anticipate what might come next. Researching the history or timeline of a product, technology, or service gives us insights so we can calculate more accurately predictions of what might happen in the future. When working with people and timelines we gain knowledge that helps us to predict what this person may do. Environmental timelines can give us this same ability. Generating timelines provides us with accurate information in order to anticipate what comes next. This information is important to consider as designers, but there is more to contemplate.

Forces outside the product need to be considered since they influence design. External forces relating to the product impact design parameters. These may include politics, government regulations, policies, and corporate profits. If we know these forces we can design to them or challenge them. Internal forces for people are the visceral emotions that move us and can explain why people do what they do. Forces of nature relating to the environment can be specific to a location, region, or broader area. This reveals how surrounding forces influence systems on a small or large scale. Information relating to these various forces affect design and are critical in driving the decision making process for designers.

Researching and discovering systems from a holistic perspective is critical. Systems relating to the product basically involve looking closely at the components and how they work together. Optimizing the location of subcomponents within a product or vehicle to enhance the design is what all good designers should already be doing. Applying sustainable development practices is critical early on in the design process. Mental models and patterns influence how people make choices through their individual perspectives, which determine how they process information and make judgments. This resolves the choices they make, which directly links to whether they will accept or reject a new product. This is important to understand when introducing new systems and products. Looking at how a product integrates into the environment gives designers a broader perspective of systems as a whole. This can be extremely powerful in implementing strategic design opportunities that lead to the transformation of systems.

\subsection{Example of product with systems}

Numerous examples of products designed with aspects of systems thinking merged into the design process can be found in production today. For example, bike-sharing schemes are a form of alternative transportation. Initiated first in 1960's in Europe, bike-sharing has been getting popular in the United States where car ownership is a strong part of the culture. The number of cities that have bike-sharing systems is drastically increasing. Cities are providing better infrastructure for this system to encourage urban dwellers and tourists to use bike-sharing options instead of driving.

The following section describes two very different scenarios of contrasting scales where systems are an integral part of the concept.

\subsubsection{Elon Musk the awakened designer}

Elon Musk is the CEO of Tesla Motors and has recognized challenges with the current energy and transportation situation. Tesla Motors has developed technologies that have advanced vehicle electrification and is currently producing the Tesla product line of allelectric vehicles. In order to make a support structure for these electric vehicles, Musk is implementing a system of Supercharging stations across the United States [2]. This greatly enhances the services and user experiences related to electric vehicle ownership. Without such a holistic system, customers may be reluctant to move from a combustion-powered engine to an all-electric vehicle.

Musk has also helped start and is the chairman of SolarCity [13], a company that designs, finances, and installs solar energy systems. SolarCity retrofits and builds charging stations for electric vehicles. Tesla Motors supplies advanced batteries and technology that SolarCity turns into energy storage systems for customers. Clearly SolarCity and Tesla Motors are excellent 
examples of advanced systems integration. These companies and the products produced are transforming existing infrastructure for transportation and technology through progressive innovation. Musk is also on the Board of Trustees of XPRISE [17], which is a highly motivating and inspiring competition that is a catalyst for positive change. Additionally, the Musk Foundation promotes and focuses on environmentally friendly renewable energy sources.

When connecting these various accomplishments together it becomes clear that Musk is operating and thinking as an awakened designer. These are achievements at the highest level. Musk breaks away from the collective consciousness of what has been done before and makes different choices. This awareness extends beyond him, although as an awakened designer he is vitally important and a powerful leader.

\subsubsection{Global collaborative project - The Portable Assisted Mobility Device}

University of Cincinnati [16] faculty and students from Industrial Design, Graphic Communication Design, and Mechanical Engineering participated in the Partners for the Advancement of Collaborative Engineering Education (PACE [10]) Global Competition titled the "Portable Assisted Mobility Device." Seven global collaborative teams competed in this competition, with each team consisting of 4 to 5 different universities with engineering and industrial design students from around the world. University of Cincinnati worked on the project for two academic years.

From the College of Design, Architecture, Art, and Design [15], Professor Brigid O'Kane led the Industrial Design students and Professor Ben Meyer led the Graphic Communication Design students. Professor Sam Anand led students from the College of Engineering and Applied
Science. Professor Manuel Löwer from Aachen University in Germany was the lead for engineering overall, since they were designated the lead 'Host' Engineering Institution for the entire team. This global team also included engineers from four other universities including, Michigan Technological University in the United States, Technische Universitaet Darmstadt in Germany, and Tecnologico de Monterrey in Mexico.

Industrial Design student Heesung Jang's GoSozo concept was selected as the winning design (Fig. 3a), which was developed as a CAD model. Soojin Kim, also a student from the University of Cincinnati became the lead designer for the second phase of this project. Systems Thinking Methodologies were incorporated during the design development process, which improved the overall concept. There were several challenges with the original design that were redeveloped and the global team worked to redesign and reengineer the entire product (Fig. 3b). The final GoSozo 2.0 was part of a large ride-share system with strategically placed charging stations within an urban environment. The product seamlessly integrated with mobile devices for ease of use. This comprehensive concept was presented at the 2014 PACE Global Annual Forum in Torino Italy. A physical running prototype of the mobility device was built (Fig. 3c) and tested on a track with the six other global teams. The track consisted of tight turns, an obstacle course, speed bumps, stairs, and a long straightaway. This final concept won six different awards, including first place overall.

\section{Meaningful technology}

Advancements in science and technology have made great contributions to society, especially in the areas of transportation, medicine, agriculture, communication, defense, and energy. With this growth, we have the perception that we are moving forward with better tools

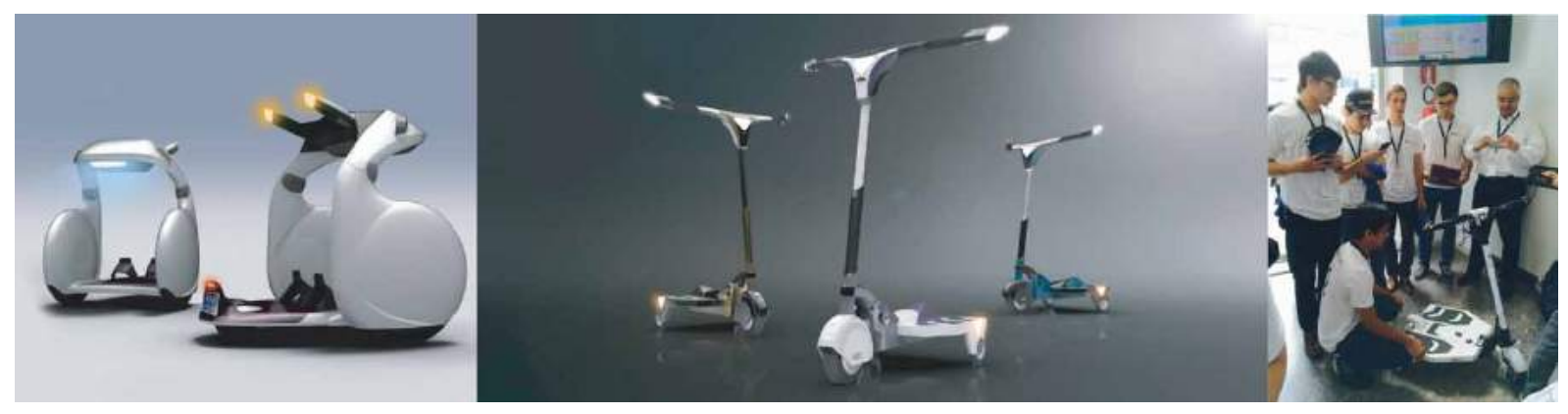

Figure 3. These three images show the development process for a Portable Assisted Mobility Device. Various stages of this process are shown from left to right. A three-dimensional digital model of the concept by Industrial Designer Heesung Jang (a) was designed in the first year of the project. In the second year Industrial Designer Soojin Kim redesigned to product (b). The final image shows the running prototype (c), which was built largely by Engineers through a collaborative effort with Industrial Designers. 


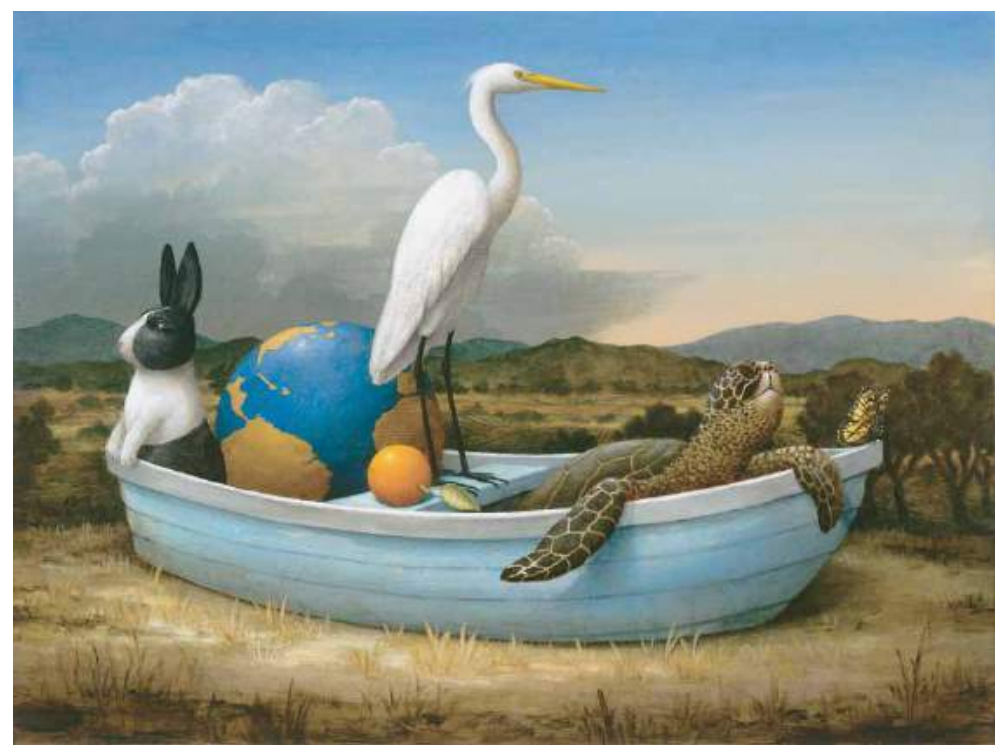

Figure 4. This painting by Kevin Sloan titled The Ark represents the idea of mobility in the broadest sense, which includes all life on earth. This $36^{\prime \prime} \times 48^{\prime \prime}$ painting was completed in 2007-2008 and is incorporated in this paper by permission of the artist.

and information. However, with these advancements we have the responsibility of making choices on how best to use it. Technology can be used for good, but more often than not we fall into the trap of using it in ways that we are most familiar with. These repeated processes are not always good from a holistic world-view. Even technology used with good intentions can cause unforeseen problems.

Many believe that science and technology will develop solutions to numerous issues we face today, including the challenges mentioned at the beginning of this paper relating to transportation. However, we must be careful with the idea that science and technology alone will resolve these issues because our use of technology is largely responsible for creating many of the problems we are currently trying to solve. If we replicate the same processes for developing and using technology we will likely get the same result. Additionally, many processes today include an increasing emphasis on using technology to move fast, think fast, and profit fast. Often times when we move so fast with these advancements we dismiss the bigger picture, which can have long-term effects. Without considering this broader perspective we are operating with partial knowledge. Thinking only in terms of developing technology is like working within our flawed design process, which only considers a small aspect of the bigger picture. Working in isolation can cause bigger problems. Collaborative practices that include different disciplines and perspectives are more likely to lead to more successful developments.
When working collaboratively we are more likely to infuse deeper and broader thinking into this development processes for a more holistic approach. Creating multidisciplinary teams that include a range of different perspectives is a means to achieving this goal. If designers continue to repeat the traditional development process, innovative solutions are less likely to be created. Technology used to support this flawed process will not lead to new solutions. Alternative perspectives will assist designers in how to properly consider a more mindful use of technology.

Some believe that people are independent or separate from nature because of our advanced knowledge and technology, which has elevated us beyond the natural world. In doing so, people easily dismiss the source from which we all have come. When we consider the water we drink, the food we digest, and the synapse impulses within our brain, we see our connection with Nature and that we are not separate from it. When we take into consideration our nature we complete that loop and explore this separateness from a perspective of whole knowledge. When we do this, we realize we are an essential part of Nature and we are not complete without it. Biologist, researcher, theorist, and author Edward O. Wilson states, "Humanity is a biological species, living in a biological environment, because like all species, we are exquisitely adapted in everything: from our behavior, to our genetics, to our physiology, to that particular environment in which we live. The earth is our home. Unless we preserve the rest of life, as a sacred duty, we will be endangering 
ourselves by destroying the home in which we evolved, and on which we completely depend."

A holistic worldview from different perspectives and scales is needed when developing products. The broad impact human technology may have on the environment should also be considered during the design phase. Above is a painting by Kevin Sloan (Fig. 4) titled The Ark, which represents the idea of mobility and moving the world in the broadest sense. Human technology and how it is used affects the natural world. This should be seriously considered when developing products and using technology. Author Wendell Berry states, "Whether we and our politicians know it or not, Nature is party to all our deals and decisions, and she has more votes, a longer memory, and a sterner sense of justice than we do."

\section{Conclusion}

Systems thinking leans toward a state of balance, considers social-ecological networks, and is able to influence a structure's trajectory. It integrates creative and scientific approaches into the design development process. When this happens we may witness the development of significant shifts in new products, processes and services that are better for the environment and successful within the market place. Systems thinking methodologies give innovative teams essential tools for a deeper understanding of our actions, social phenomena, and environmental issues. These methodologies allow designers to develop solutions from a more informed perspective. As a result we are able to discover new and appropriate paths in developing innovative products and systems that are holistic solutions for challenges today and in the future.

\section{ORCID}

Brigid O'Kane (ㄴ) http://orcid.org/0000-0002-5041-3722

\section{References}

[1] Bronson, P.; Merryman, A.: The Creativity Crisis, News week, 2010, http://www.newsweek.com/creativity-crisis74665

[2] Bullis, K.: How Tesla Is Driving Electric Car Innovation, MIT Technology Review, 2013, http://www.technology review.com/news/516961/how-tesla-is-driving-electriccar-innovation/

[3] The Daily Beast: America's 50 Worse Commutes, 2011, http://www.thedailybeast.com/articles/2011/03/08/50worst-commutes-americas-highways-to-hell.html

[4] Gardner H.: Frames of Mind, The Theory of Multiple Intelligences, Basic Books, New York, 1993.

[5] Kolb, D.: Experiential Learning, Experience as the Source of Learning and Development, second edition, Pearson Education, Inc. New Jersey, 2015.

[6] Lewin, K: Principles of Topological Psychology, Read Books Ltd., 2013.

[7] McMaster, R.: The 8 Types of Creative Intelligence, http://lateralaction.com/articles/multiple-intelligences/

[8] Mitchell, W.; Borroni-Bird, C.; Burns, L.: Reinventing the Automobile, Personal Urban Mobility for the 21st Century, Massachusetts, MIT Press, 2010.

[9] O'Kane, B.: Advancing the Concept Development Process with System Thinking, Computer-Aided Design \& Applications, 11(S1), 2014, S44-S53. http://dx.doi.org/10.1080/ 16864360.2014 .914408

[10] Partners for the Advancement of Collaborative Engineering Education, http://pacepartners.org

[11] Piaget, J.; Inhelder, B.: The Psychology of the Child, Basic Books, Inc., New York, 1969, 2000.

[12] Senge, P.: The Fifth Discipline: The Art \& Practice of the Learning Organization, United States, Currency, 1990.

[13] SolarCity, http://www.solarcity.com

[14] Wilber, K.: A Theory of Everything, An Integral Vision for Business, Politics, Science and Spirituality, Shambhala Publications, Inc., Boston Massachusetts, 2001.

[15] University of Cincinnati, College of Design, Architecture, Art, and Planning, http://daap.uc.edu

[16] University of Cincinnati, College of Engineering and Applied Science, http://ceas.uc.edu/.html

[17] XPRIZE, http://www.xprize.org 